\title{
A 10-year study of Alternaria and Cladosporium in two Polish cities (Szczecin and Cracow) and relationship with the meteorological parameters
}

\author{
Agnieszka Grinn-Gofroń • Agnieszka Strzelczak • \\ Danuta Stępalska $\cdot$ Dorota Myszkowska
}

Received: 1 June 2015/Accepted: 3 November 2015/Published online: 14 November 2015

(C) The Author(s) 2015. This article is published with open access at Springerlink.com

\begin{abstract}
Alternaria and Cladosporium spores belong to the most frequent and allergenic particles in bioaerosol in the temperate climate. The investigation of Alternaria and Cladosporium spore concentrations was performed in two cities in Poland, Szczecin and Cracow, in 2004-2013. The meteorological parameters taken to assess their impact on fungal spores were average, maximum and minimum temperature, relative humidity and average wind velocity. In order to reveal whether changes in dynamics of spore seasons are driven by meteorological conditions, ordination methods were applied. Canonical correspondence analysis was used to explore redundancy among the predictors
\end{abstract}

A. Grinn-Gofroń ( $₫)$

Department of Plant Taxonomy and Phytogeography, University of Szczecin, Wąska 13, 71-415 Szczecin, Poland

e-mail: agofr@univ.szczecin.pl

\section{A. Strzelczak}

Department of Process Engineering, West Pomeranian University of Technology, Szczecin, Poland

\section{Stępalska}

Institute of Botany, Jagiellonian University, Cracow, Poland

\section{Myszkowska}

Department of Clinical and Environmental Allergology, Jagiellonian University Medical College, Cracow, Poland (meteorological parameters). Prior to ordination analyses, the data were $\log (x)$-transformed. Concentrations of Alternaria and Cladosporium spores were significantly higher in Szczecin comparing to Cracow, but it was also observed the decreasing trend in the spore concentrations in Szczecin. As regards temperature, it was higher in Cracow and was still increasing in the studied years. Relative humidity and wind velocity were significantly lower in Cracow. In Szczecin meteorological conditions did not explain changes in spore season characteristics (insignificant redundancy analysis models), while in Cracow's redundancy analysis models indicated that spore season parameters were in over $40 \%$ determined by meteorological conditions, mainly air temperature and wind velocity. If they increase, the peak value, total number of spores and their average concentrations in a season will also increase.

Keywords Temporal trend aerobiological monitoring $\cdot$ Meteorological parameters $\cdot$ Fungi spores $\cdot$ Spore season $\cdot$ Ordination method

\section{Introduction}

Fungal spores constitute a significant component of bioaerosol and can be found in the air at almost any time throughout the year. Most fungal species act saprotrophically, colonizing all stages of plant growth, or as plant pathogens, prompting considerable 
economic losses worldwide (Hjelmroos 1993; Infante et al. 1999a, b). Cladosporium and Alternaria are the most cosmopolitan fungi, particularly in temperate regions, due to their almost permanent presence outdoor and indoor (Infante et al. 1999a, b; D'Amato 1981; Ricci et al. 1995).

Cladosporium is the most abundant spore type in many outdoor environments, accounting for 40-80\% of the total spore count in many European cities (Spieksma 1995), while Alternaria is included in many studies because of its importance in the agricultural sector due to its pathogenicity towards different crops such as potatoes (Iglesias et al. 2007). Both spore types are of clinical importance because they are considered to be allergenic (Kurup et al. 2002). The monitoring of fungal spores in Poland revealed the summer as the most favourable season for Alternaria and Cladosporium occurrence (Stępalska et al. 1999; Konopińska 2004; Grinn-Gofroń and Strzelczak 2008a, b).

In the present study, we investigate the daily Alternaria and Cladosporium concentrations in two cities of Poland-Szczecin and Cracow. The main goals of the research were to: (1) broaden the global knowledge on airborne spore dynamics based on the first Polish long-term data for a multiannual period (2004-2013); (2) reveal long-term trends of changes in spore season characteristics, (3) assess the driving factors of those changes in relation to meteorological conditions.

\section{Materials and methods}

The investigation of the Alternaria and Cladosporium daily spore concentrations in the atmosphere was carried out in two cities in Poland, Szczecin and Cracow, in 2004-2013 (Fig. 1). Both cities are surrounded by forests, farmlands and abandoned farmland areas which provide suitable media for the spore production. The maritime climate of Szczecin is influenced by impact of the air masses from over the Northern Atlantic. Most often the polar air masses are characterized by high humidity, which affects the growth of the summer cloud cover and amount of precipitation. Winter is associated with warming and high cloudiness. These masses are most common in summer and autumn. The mean annual temperature is $8.6{ }^{\circ} \mathrm{C}$ and the annual precipitation- $550 \mathrm{~mm}$. The average wind speed is $3.3 \mathrm{~m} \mathrm{~s}^{-1}$ and western (W) and south-western (SW) wind directions are dominant (Woś 1999).

Cracow is situated in a region where weather changes are frequent due to the friction of both humid air masses arriving from over the Northern Atlantic Ocean and dry, continental masses of air incoming from the east. So the climate in Cracow is characterized by hot summers and cold winters. The mean annual temperature is $8.7^{\circ} \mathrm{C}$ and the annual precipitation- $750 \mathrm{~mm}$, The prevailing wind directions are western (W) and south-western (SW), and the average wind speed is $1.9 \mathrm{~m} \mathrm{~s}^{-1}$ (Woś 1999).

Growing seasons in the cities differ in length: 210-220 days in Szczecin and over 220 days in Cracow (Woś 1999).

For this study, the volumetric method has been employed using the Hirst spore trap (Hirst 1952) "Lanzoni s.r.l. trademark" with a flow rate of $10 \mathrm{~L} \mathrm{~min}^{-1}$. The traps were installed on the roof tops in the centres of the cities at the same height $(20 \mathrm{~m})$ above ground level.

Airborne spores were sampled continuously, 12 months a year during the study period. The Melinex tape used for catching spores was replaced at the same day every week and cut into segments corresponding to 24-h periods. Results (average daily concentration) were expressed as the number of spores $\mathrm{m}^{-3}$ air $24 \mathrm{~h}^{-1}$.

The daily values of meteorological parameters taken into consideration to assess their effect on the airborne fungal spores were: average air temperature (Av_Temp), maximum air temperature (Max_Temp), minimum air temperature (Min_Temp), relative humidity $(\mathrm{RH})$ and average wind velocity (Av_wind_vel). In Szczecin the meteorological data covering 10 years of the study were provided by the automatic weather station (Vaisala MAWS101 and MAWS201, Finland). The meteorological station was located in the immediate neighbourhood of the aerobiological trap. In Cracow the meteorological data were obtained from the meteorological Web database (http://www. meteo.pl/).

The spore data were analysed to determine the start, the end and the duration (Duration) of the season using the $90 \%$ method. The start of the season (S_Start) was defined as the date when $5 \%$ of the seasonal cumulative spore count was trapped and the end of the season (S_End) as the date when $95 \%$ of the seasonal cumulative spore count was reached (British 

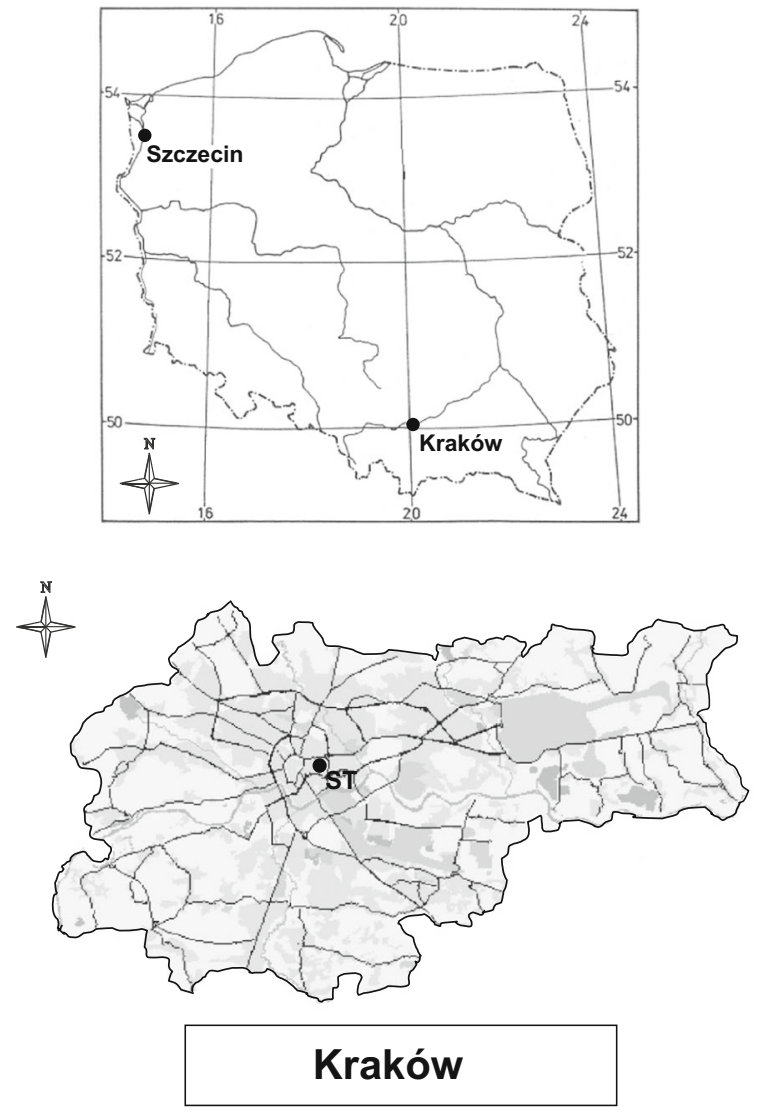

Fig. 1 Location of sampling sites

Aerobiology Federation 1995). Additionally, the following spore season parameters were investigated: average spore concentrations (Av_conc), peak value (Peak_value), peak day (Peak_day) and total number of spores (TNS).

The daily concentrations of spores and the values of meteorological factors formed a 10 -year-long time series. Differences between the study sites were assessed with the $U$ Mann-Whitney test (1947). Time series trends in the daily concentrations and meteorological parameters were determined using linear regression analysis with the focus on slope coefficients and their significance. Similar analysis was applied for spore season parameters and meteorological parameters averaged for each year. All those calculations were performed in Statistica 10 (StatSoft 2011).

In order to reveal whether changes in the dynamics of spore seasons are driven by meteorological conditions, ordination methods were applied. Ordination primarily endeavours to represent complex,

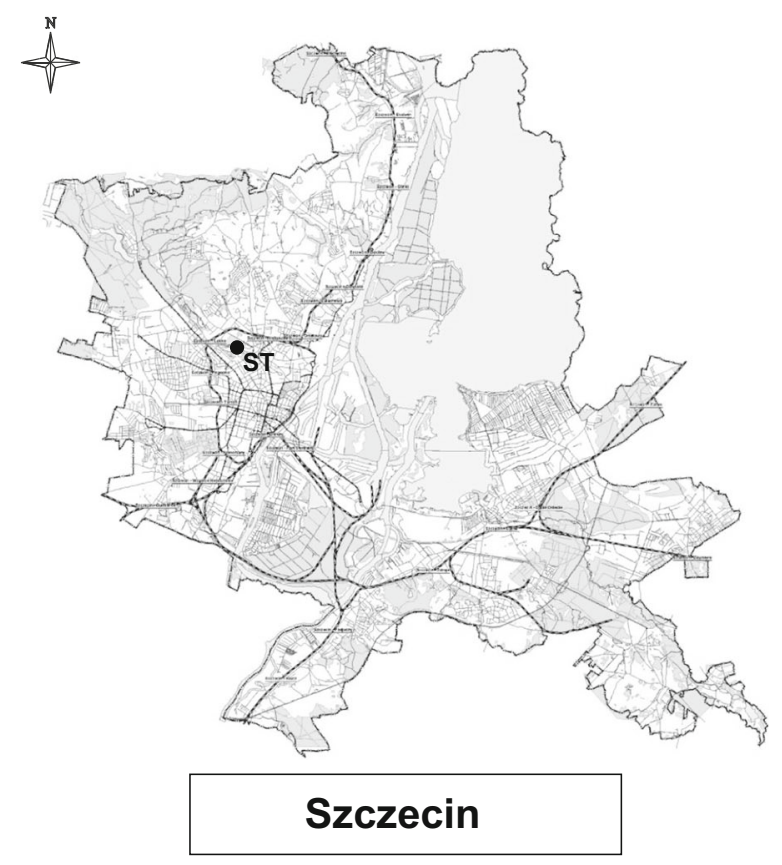

multivariate relationships as correctly as possible in a low-dimensional space (Gauch 1982). The reasons for using that kind of statistical analysis were as follows: (1) the data set included multiple dependent (spore season parameters) and independent variables (meteorological factors); (2) a single multivariate analysis saves time, in contrast to a separate univariate analysis for each dependent variable; (3) ideally and typically, dimensions of the "low-dimensional space" will represent important and interpretable environmental gradients; (4) ordination is a noise reduction technique (Gauch 1982); (5) possibility of determining the relative importance of different gradients (impossible with univariate techniques).

In this study, redundancy among the predictors (meteorological factors) was explored with the variance inflation factor (VIF) in the canonical correspondence analysis (CCA; ter Braak and Prentice 1988) which considered both the environmental parameters and spore season characteristics. VIF analysis is a 
diagnostic tool used to identify useless constraints. A common rule is that values over 10 indicate redundant constraints (Gross 2003). Using detrended correspondence analysis (DCA) for the dependent variables (spore season characteristics), the gradient of DCA first axis was determined, which indicated the use of either CCA (unimodal responses) or redundancy analysis (RDA, monotonic responses) (Legendre and Legendre 1998; ter Braak 1995) in the final analysis. Significance of consecutive axes was assessed with the ANOVA like permutation test. CCA, DCA and RDA analyses were performed in the $\mathrm{R}$ environment (The $\mathrm{R}$ Foundation for Statistical Computing 2009) using the CCA (Legendre and Legendre 1998), DECORANA (Hill and Gauch 1980; Oksanen and Minchin 1997), RDA (Legendre and Legendre 1998) and ANOVA.CCA (Legendre et al. 2011) functions of the vegan package.

Prior to ordination analyses, the data were $\log (x)$ transformed. The primary reason for such a transformation was that a 1-unit difference in an explanatory variable may potentially has higher importance at its low values than at high level, and then, logarithmic transformation is recommended (Palmer 1993). Moreover, the $\log$ transformation unified the levels of dependent parameters and dampened the influence of outliers.

\section{Results}

Daily a 10-year-long time series of Alternaria and Cladosporium spore concentrations is presented in Figs. 2 and 3. In general, the abundance of spores was significantly higher in Szczecin comparing to Cracow (Table 1). Due to relatively short spore seasons and the absence of spores for the great part of a year, medians are much lower than the average values. The study sites differed also in meteorological conditions - the average, maximum and minimum temperatures in Cracow were higher but the relative humidity and average wind velocity were significantly lower. Therefore, time series trends were determined with linear regression analysis separately for each site.

Linear trends of changes (slope coefficients in linear regression equations) for the daily spore concentrations and daily meteorological conditions in the studied period are presented in Table 2 .

This analysis revealed the significant decreasing trend in the concentrations of both Alternaria and

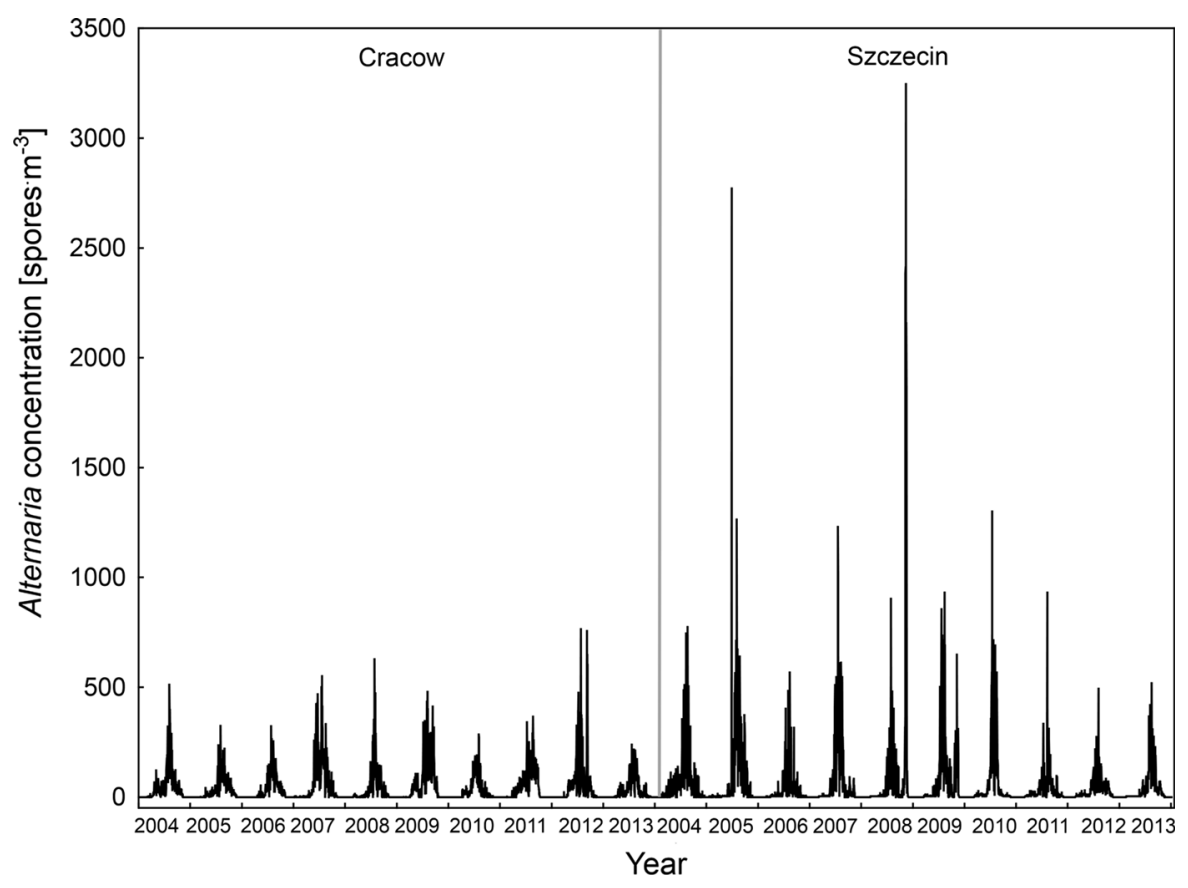

Fig. 2 Daily average concentrations of airborne Alternaria spores in Cracow and Szczecin in 2004-2013 


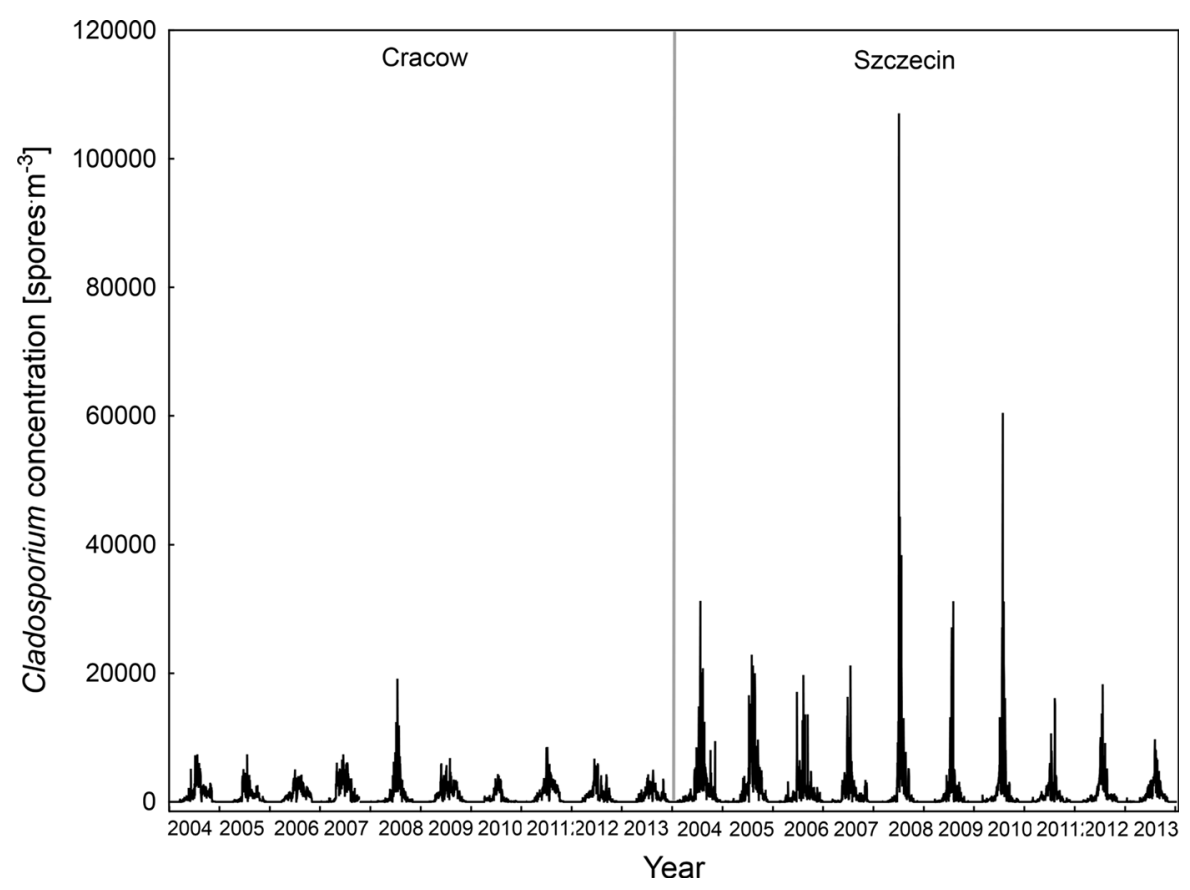

Fig. 3 Daily average concentrations of airborne Cladosporium spores in Cracow and Szczecin in 2004-2013

Cladosporium spores in Szczecin and the decline in wind velocity. Temperatures increased, however, insignificantly. In turn, the rise in temperatures in Cracow was not accompanied by significant changes in spore abundances.

In the next step, we focused on the parameters describing spore seasons' characteristics for each year (Table 3) against a background of changes in yearly average meteorological parameters (Table 4).

The analysis of linear trends of changes in spore seasons and yearly average meteorological parameters revealed only two slope coefficients (Table 5) Alternaria spore seasons in Szczecin tended to appear earlier by around 4 days per year. Humidity in Cracow decreased by slightly above $3 \%$ per year. However, there were a few parameters with only slightly insignificant ( $p$ level around 0.1 ) slope coefficients. They indicated the tendency for the earlier start of Alternaria and Cladosporium spore seasons in Cracow as well as earlier occurrence of the Alternaria peak day. For Szczecin, those coefficients were decreasing in spore concentrations and total number of spores.

In order to reveal whether changes in the dynamics of spore seasons are driven by meteorological conditions, the ordination methods were applied. Analyses were performed separately for each spore species. For Szczecin, no significant model was obtained.

For Alternaria in Cracow, the values of VIF coefficients from CCA analysis were $<10$ for the set of meteorological parameters excluding average air temperature (Max_Temp-4.3, Min_Temp-4.8, RH-1.8, Av_wind_vel-2.5). The next stage of the investigation involved DCA, which was used to determine environmental gradients for subsequent parameters of spore seasons. Values $<2$ indicated the monotonic responses. Therefore, RDA was performed in the final stage. The ANOVA permutation test confirmed the significance of only RDA1 axis $(p<0.05)$ which explained $42 \%$ of the total variance. Figure 4 presents the obtained RDA biplot.

Air temperatures and wind velocity had positive contribution to RDA1 (Fig. 4, Table 6) while humidity negative. The RDA biplot (Fig. 4) shows that meteorological conditions in a 10 -year-long period determined mainly the peak value, the average Alternaria concentrations and the total number of spores. Their levels increased with air temperatures and wind velocity and decreased with humidity.

For Cladosporium in Cracow, the values of VIF coefficients from CCA analysis were $<10$ for 
Table 1 Statistical characteristics of the daily spore concentrations and meteorological parameters recorded in the studied sites in 2004-2013

* Statistically significant differences between the sites using $U$ MannWhitney test $(p<0.05)$

\begin{tabular}{|c|c|c|c|c|}
\hline \multirow[t]{2}{*}{ Variable } & \multicolumn{2}{|l|}{ Cracow } & \multicolumn{2}{|l|}{ Szczecin } \\
\hline & Mean $\pm \mathrm{SD}$ & Median & Mean $\pm \mathrm{SD}$ & Median \\
\hline * Alternaria (spores $\mathrm{m}^{-3}$ ) & $39.0 \pm 72.3$ & 5.0 & $56.0 \pm 161.0$ & 6.0 \\
\hline * Cladosporium (spores $\mathrm{m}^{-3}$ ) & $882.4 \pm 1375.0$ & 205.5 & $1395.9 \pm 3927.5$ & 220.0 \\
\hline * Av_Temp $\left({ }^{\circ} \mathrm{C}\right)$ & $9.4 \pm 8.6$ & 10.0 & $8.8 \pm 7.8$ & 9.2 \\
\hline * Max_Temp $\left({ }^{\circ} \mathrm{C}\right)$ & $14.5 \pm 10.1$ & 15.2 & $13.7 \pm 8.9$ & 14.1 \\
\hline * Min_Temp $\left({ }^{\circ} \mathrm{C}\right)$ & $5.5 \pm 7.8$ & 5.9 & $4.1 \pm 7.0$ & 4.0 \\
\hline$* \mathrm{RH}(\%)$ & $75.7 \pm 12.1$ & 77.0 & $80.4 \pm 13.0$ & 82.6 \\
\hline * Av_wind_vel $\left(\mathrm{m} \mathrm{s}^{-1}\right)$ & $1.6 \pm 0.9$ & 1.3 & $3.2 \pm 1.4$ & 3.0 \\
\hline
\end{tabular}

Table 2 Linear trends of changes in daily spore concentrations and meteorological parameters recorded in the studied sites in 2004-2013

\begin{tabular}{|c|c|c|c|c|c|c|c|}
\hline Parameters & $\begin{array}{l}\text { Alternaria } \\
\left.\text { (spores year }^{-1}\right)\end{array}$ & $\begin{array}{l}\text { Cladosporium } \\
\text { (spores year }^{-1} \text { ) }\end{array}$ & $\begin{array}{l}\text { Av_Temp } \\
\left({ }^{\circ} \mathrm{C} \text { year }^{-1}\right)\end{array}$ & $\begin{array}{l}\text { Max_Temp } \\
\left({ }^{\circ} \mathrm{C} \text { year }{ }^{-1}\right)\end{array}$ & $\begin{array}{l}\text { Min_Temp } \\
\left({ }^{\circ} \mathrm{C} \text { year }^{-1}\right)\end{array}$ & $\begin{array}{l}\text { RH } \\
\left(\% \text { year }^{-1}\right)\end{array}$ & $\begin{array}{l}\text { Av_wind_vel } \\
\left(\mathrm{m} \mathrm{s}^{-1} \text { year }^{-1}\right)\end{array}$ \\
\hline Cracow & 0.33 & -12.48 & $0.07 * * *$ & $0.11 *$ & $0.07 * * *$ & $-0.26 * *$ & -0.01 \\
\hline Szczecin & $-3.65 * * *$ & $-84.4 * * *$ & 0.03 & 0.02 & 0.04 & 0.01 & $-0.02 * *$ \\
\hline
\end{tabular}

* Slope coefficients significantly different from zero at $p<0.05$; ** slope coefficients significantly different from zero at $p<0.01$; $* * *$ slope coefficients significantly different from zero at $p<0.001$

maximum and minimum temperatures, humidity and wind velocity (4.3, 4.8, 1.8 and 2.5 , respectively). DCA also indicated monotonic responses of spore season parameters to meteorological parameters (gradient of first DCA axis <2), and then, RDA was performed. The ANOVA permutation test confirmed the significance of only RDA1 axis $(p<0.05)$ which explained $43 \%$ of the total variance. Figure 5 presents the obtained RDA biplot.

RDA1 was mainly connected with air temperatures and wind velocity, and their contribution was positive (Fig. 5, Table 6). The RDA biplot (Fig. 5) shows that meteorological conditions determined mainly the peak value, the average Cladosporium concentrations and the total number of spores. Their levels decreased with air temperatures and wind velocity.

\section{Discussion}

Analysis of Alternaria and Cladosporium daily spores concentration revealed their significantly higher concentrations in Szczecin in comparison with Cracow. It could result from different values of meteorological parameters influencing daily concentrations in Szczecin and could possibly be explained by variability in weather conditions caused by the vicinity of the Baltic Sea.
In Cracow maximum, minimum and average temperatures were higher than in Szczecin, but relative humidity and average wind velocity were significantly lower. The relationship between fungal spore levels and prevailing meteorological factors was observed also by other authors. A strong positive relationship was found between Alternaria spore concentrations and mean, minimum and maximum temperature (Angulo-Romero et al. 1999; Sabariego et al. 2000; Burch and Levetin 2002), between concentrations and maximum temperature (Corden and Millington 2001; Mitakakis et al. 2001; Stępalska and Wołek 2005) and between concentrations and mean temperature (Munuera Giner et al. 2001; Troutt and Levetin 2001). Grinn-Gofroń and Rapiejko (2009) suggest that Alternaria and Cladosporium spore concentrations are mainly influenced by air temperature, but in the spore release a key role play others factors like: changes in relative humidity and wind speed (Sadyś et al. 2014; Fernández-Rodríguez et al. 2015). A strong association between average daily temperature and average daily Alternaria and Cladosporium spore concentrations was reported also in Zagreb (Peternel et al. 2004). This variability is due to the proximity and abundance of the source of fungal spores and the geobotanical characteristics of studied regions. Some authors indicate the dependence of spore concentrations on the crop production and proximity of 
Table 3 Characteristics of spore seasons (average concentration, season start, season end, season duration, peak value, peak day, TNS - total number of spores) recorded in the studied sites in 2004-2013

\begin{tabular}{|c|c|c|c|c|c|c|c|c|c|}
\hline Site & Taxon & Year & $\begin{array}{l}\text { Av_conc } \\
\left(\text { spores } \mathrm{m}^{-3}\right)\end{array}$ & $\begin{array}{l}\text { S_Start } \\
\text { (dd-mm) }\end{array}$ & $\begin{array}{l}\text { S_End } \\
\text { (dd-mm) }\end{array}$ & $\begin{array}{l}\text { Duration } \\
\text { (days) }\end{array}$ & $\begin{array}{l}\text { Peak_value } \\
\left(\text { spores } \mathrm{m}^{-3}\right)\end{array}$ & $\begin{array}{l}\text { Peak_day } \\
\text { (dd-mm) }\end{array}$ & $\begin{array}{l}\text { TNS } \\
\text { (spores) }\end{array}$ \\
\hline \multirow[t]{20}{*}{ Cracow } & \multirow[t]{10}{*}{ Alternaria } & 2004 & 41.7 & $02-05$ & $08-10$ & 160 & 511 & $05-08$ & 13,791 \\
\hline & & 2005 & 30.5 & 03-06 & $15-10$ & 135 & 324 & 02-08 & 9841 \\
\hline & & 2006 & 28.4 & $14-06$ & $04-10$ & 113 & 322 & $26-07$ & 9338 \\
\hline & & 2007 & 56.7 & 24-05 & $12-09$ & 112 & 550 & $20-07$ & 18,867 \\
\hline & & 2008 & 32.9 & $15-06$ & $15-09$ & 93 & 627 & $26-07$ & 10,856 \\
\hline & & 2009 & 52.1 & 04-05 & $27-09$ & 147 & 479 & 04-08 & 17,215 \\
\hline & & 2010 & 27.1 & 01-05 & $16-09$ & 139 & 284 & $02-08$ & 8958 \\
\hline & & 2011 & 44.7 & 03-05 & $22-09$ & 143 & 340 & 09-07 & 14,757 \\
\hline & & 2012 & 49.9 & 09-05 & $25-09$ & 140 & 764 & $24-07$ & 16,545 \\
\hline & & 2013 & 25.3 & $06-05$ & $12-10$ & 160 & 238 & $19-07$ & 8358 \\
\hline & \multirow[t]{10}{*}{ Cladosporium } & 2004 & 1000.8 & $19-05$ & $28-10$ & 163 & 7075 & $07-07$ & 330,135 \\
\hline & & 2005 & 690.1 & $14-06$ & $12-10$ & 121 & 7228 & $20-07$ & 222,223 \\
\hline & & 2006 & 896.2 & $05-05$ & $14-10$ & 163 & 4860 & $02-07$ & 295,345 \\
\hline & & 2007 & 1165.4 & $29-04$ & $30-08$ & 124 & 5977 & $17-07$ & 384,817 \\
\hline & & 2008 & 992.3 & $24-05$ & 07-09 & 107 & 18,984 & $15-07$ & 328,229 \\
\hline & & 2009 & 982.3 & 03-05 & $30-09$ & 151 & 6640 & $30-07$ & 323,583 \\
\hline & & 2010 & 470.3 & $28-04$ & $25-08$ & 120 & 4177 & $12-07$ & 154,464 \\
\hline & & 2011 & 1067.0 & 06-05 & $22-09$ & 140 & 8376 & 08-07 & 352,039 \\
\hline & & 2012 & 890.6 & $19-04$ & $25-09$ & 160 & 5577 & 09-07 & 294,302 \\
\hline & & 2013 & 663.0 & $17-05$ & $31-10$ & 168 & 4814 & $12-08$ & 218,160 \\
\hline \multirow[t]{20}{*}{ Szczecin } & \multirow[t]{10}{*}{ Alternaria } & 2004 & 62.9 & $29-04$ & $12-10$ & 167 & 774 & 07-08 & 17,742 \\
\hline & & 2005 & 87.9 & 04-07 & $04-10$ & 93 & 1236 & $30-07$ & 26,140 \\
\hline & & 2006 & 32.5 & $21-06$ & $09-10$ & 111 & 567 & 09-08 & 10,651 \\
\hline & & 2007 & 69.3 & $11-06$ & $20-08$ & 71 & 1230 & $16-07$ & 21,511 \\
\hline & & 2008 & 90.7 & $22-06$ & 11-09 & 51 & 903 & $26-07$ & 11,719 \\
\hline & & 2009 & 67.6 & $19-06$ & $15-09$ & 150 & 930 & 08-08 & 19,876 \\
\hline & & 2010 & 53.8 & $11-06$ & $23-08$ & 74 & 1300 & $11-07$ & 19,683 \\
\hline & & 2011 & 33.2 & $06-06$ & $04-10$ & 121 & 930 & $05-08$ & 11,656 \\
\hline & & 2012 & 27.5 & 04-05 & $12-10$ & 161 & 472 & $02-08$ & 9051 \\
\hline & & 2013 & 35.4 & $12-06$ & $10-10$ & 121 & 518 & $12-07$ & 11,549 \\
\hline & \multirow[t]{10}{*}{ Cladosporium } & 2004 & 1878.3 & $19-05$ & $28-10$ & 163 & 31,098 & $20-07$ & 628,095 \\
\hline & & 2005 & 1917.8 & $14-06$ & $11-10$ & 120 & 22,737 & $28-07$ & 675,286 \\
\hline & & 2006 & 1276.6 & 23-05 & $16-09$ & 178 & 19,560 & 06-08 & 396,063 \\
\hline & & 2007 & 1095.9 & $15-05$ & 06-09 & 115 & 21,042 & $13-07$ & 332,550 \\
\hline & & 2008 & 2213.0 & $21-06$ & 04-09 & 75 & 106,896 & $29-06$ & 738,276 \\
\hline & & 2009 & 969.0 & $30-05$ & 08-09 & 101 & 31,054 & $28-07$ & 348,641 \\
\hline & & 2010 & 1803.1 & $02-06$ & $23-08$ & 83 & 22,300 & $30-07$ & 540,216 \\
\hline & & 2011 & 822.1 & 28-04 & 30-09 & 185 & 16,000 & 05-08 & 294,439 \\
\hline & & 2012 & 1074.7 & 09-05 & $28-09$ & 142 & 18,144 & $19-07$ & 335,113 \\
\hline & & 2013 & 922.2 & $25-05$ & $02-10$ & 130 & 9571 & $31-07$ & 303,596 \\
\hline
\end{tabular}


Table 4 Characteristics of yearly average meteorological parameters recorded in the studied sites in 2004-2013

\begin{tabular}{|c|c|c|c|c|c|c|}
\hline Site & Year & Av_Temp $\left({ }^{\circ} \mathrm{C}\right)$ & Max_Temp $\left({ }^{\circ} \mathrm{C}\right)$ & Min_Temp $\left({ }^{\circ} \mathrm{C}\right)$ & RH (\%) & Av_wind_vel $\left(\mathrm{m} \mathrm{s}^{-1}\right)$ \\
\hline \multirow[t]{10}{*}{ Cracow } & 2004 & 9.1 & 13.9 & 5.4 & 77.0 & 1.6 \\
\hline & 2005 & 8.8 & 13.9 & 4.9 & 77.5 & 1.6 \\
\hline & 2006 & 9.3 & 14.7 & 5.2 & 76.7 & 1.5 \\
\hline & 2007 & 10.1 & 15.1 & 6.2 & 75.7 & 1.7 \\
\hline & 2008 & 10.2 & 15.3 & 6.3 & 75.7 & 1.8 \\
\hline & 2009 & 9.6 & 14.5 & 5.7 & 75.7 & 1.6 \\
\hline & 2010 & 8.5 & 13.2 & 4.8 & 77.0 & 1.6 \\
\hline & 2011 & 9.8 & 15.0 & 5.7 & 73.8 & 1.7 \\
\hline & 2012 & 9.5 & 14.8 & 5.4 & 73.2 & 1.7 \\
\hline & 2013 & 9.4 & 14.3 & 5.7 & 75.3 & 1.5 \\
\hline \multirow[t]{10}{*}{ Szczecin } & 2004 & 8.6 & 13.3 & 3.8 & 80.6 & 3.4 \\
\hline & 2005 & 8.8 & 13.7 & 4.0 & 79.8 & 3.3 \\
\hline & 2006 & 9.3 & 14.2 & 4.3 & 80.1 & 3.1 \\
\hline & 2007 & 9.6 & 14.4 & 4.9 & 81.9 & 3.4 \\
\hline & 2008 & 9.4 & 14.1 & 4.9 & 79.8 & 3.3 \\
\hline & 2009 & 8.7 & 13.6 & 3.9 & 81.5 & 3.1 \\
\hline & 2010 & 7.3 & 12.1 & 2.6 & 82.2 & 3.1 \\
\hline & 2011 & 9.4 & 14.3 & 4.7 & 79.1 & 3.3 \\
\hline & 2012 & 8.7 & 13.6 & 3.9 & 80.9 & 3.3 \\
\hline & 2013 & 8.8 & 13.4 & 4.2 & 78.5 & 3.0 \\
\hline
\end{tabular}

Table 5 Linear trends of changes in spore seasons and yearly average meteorological parameters recorded in the studied sites in 2004-2013

Slope coefficients significantly different from zero at $p<0.05$ are marked in $*$, and slope coefficients at the limit of statistical significance are marked with $\bullet$

\begin{tabular}{|c|c|c|c|}
\hline & Parameters & Cracow & Szczecin \\
\hline \multirow[t]{7}{*}{ Alternaria } & Av_conc (spores year ${ }^{-1}$ ) & 0.01 & -4.46 \\
\hline & S_Start (days year ${ }^{-1}$ ) & $-2.81^{\star}$ & $-4.01 *$ \\
\hline & S_End (days year ${ }^{-1}$ ) & -0.87 & 0.14 \\
\hline & Duration (days year ${ }^{-1}$ ) & 1.94 & 1.33 \\
\hline & Peak_value (spores year ${ }^{-1}$ ) & -1.41 & -33.94 \\
\hline & Peak_day (days year ${ }^{-1}$ ) & $-1.55^{\bullet}$ & -1.44 \\
\hline & TNS (spores year ${ }^{-1}$ ) & 10.65 & -1016.13 \\
\hline \multirow[t]{7}{*}{ Cladosporium } & Av_conc (spores year ${ }^{-1}$ ) & -17.44 & $-96.37^{\star}$ \\
\hline & S_Start (days year ${ }^{-1}$ ) & $-2.62^{\bullet}$ & -1.78 \\
\hline & S_End (days year ${ }^{-1}$ ) & -1.19 & -0.93 \\
\hline & Duration (days year ${ }^{-1}$ ) & 1.42 & -1.08 \\
\hline & Peak_value (spores year ${ }^{-1}$ ) & -194.36 & -1913.71 \\
\hline & Peak_day (days year ${ }^{-1}$ ) & 1.66 & 0.65 \\
\hline & TNS (spores year ${ }^{-1}$ ) & -5548.21 & $-33,796.7^{\bullet}$ \\
\hline \multirow[t]{5}{*}{ Meteorological factors } & Av_Temp $\left({ }^{\circ} \mathrm{C}\right.$ year $\left.{ }^{-1}\right)$ & 0.03 & -0.04 \\
\hline & Max_Temp $\left({ }^{\circ} \mathrm{C}\right.$ year $\left.{ }^{-1}\right)$ & 0.03 & -0.04 \\
\hline & Min_Temp $\left({ }^{\circ} \mathrm{C}\right.$ year $\left.{ }^{-1}\right)$ & 0.02 & -0.02 \\
\hline & $\mathrm{RH}\left(\%\right.$ year $\left.^{-1}\right)$ & $-0.34^{\diamond}$ & -0.08 \\
\hline & Av_wind_vel $\left(\mathrm{m} \mathrm{s}^{-1}\right.$ year $\left.^{-1}\right)$ & 0.01 & -0.02 \\
\hline
\end{tabular}




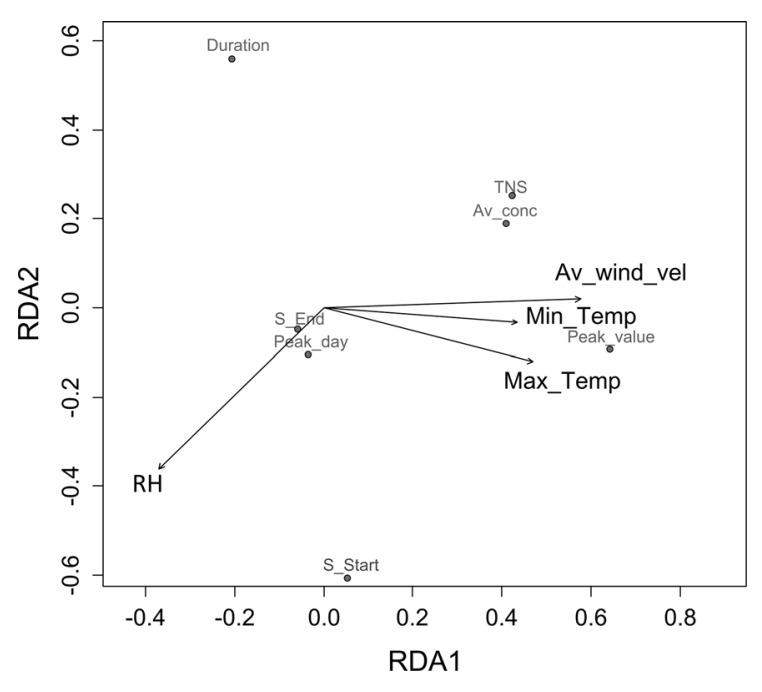

Fig. 4 RDA biplot illustrating relations between meteorological variables and Alternaria spore season parameters in Cracow in 2004-2013. Significant axis from ANOVA permutations test: RDA1. Variance explained: $42 \%$

Table 6 RDA biplot scores and variance explained by constraining meteorological variables for Alternaria and Cladosporium spore season parameters in Cracow in 2004-2013

\begin{tabular}{llc}
\hline Taxon & $\begin{array}{l}\text { Constraining } \\
\text { variables }\end{array}$ & $\begin{array}{l}\text { Biplot scores } \\
\text { RDA1 }\end{array}$ \\
\hline Alternaria & Max_Temp & 0.77 \\
& Min_Temp & 0.71 \\
& RH & -0.61 \\
Cladosporium & Av_wind_vel & 0.94 \\
& Max_Temp & 0.80 \\
& Min_Temp & 0.80 \\
& RH & -0.30 \\
& Av_wind_vel & 0.88 \\
\hline
\end{tabular}

grassland areas (Mitakakis et al. 2001; Corden et al. 2003; Pepeljnjak and Segovic 2003). Li and Kendrick (1995) found that concentrations of various fungal spores varied with mean temperature the most, but minimum temperature was the most important in the growing season. The slight correlation between Cladosporium daily spore concentration and mean temperature but not significant was noted in Cracow (Southern Poland) by Stępalska and Wołek (2005) and Mitakakis et al. (1997) reported significant, positive correlation with average temperature in Melbourne (Australia).

The sporulation and dispersion of Alternaria spores are also closely related to variation in atmospheric

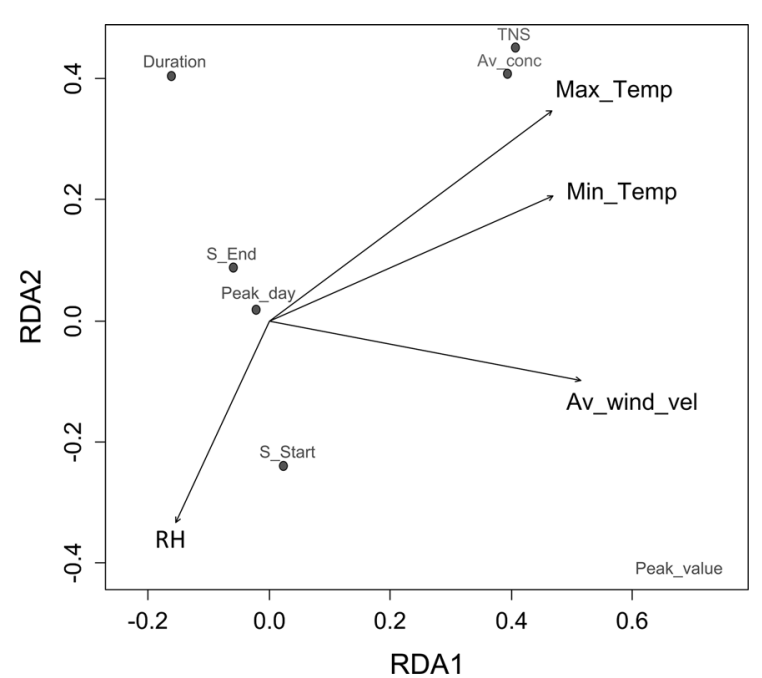

Fig. 5 RDA biplot illustrating relations between meteorological variables and Cladosporium spore season parameters in Cracow in 2004-2013. Significant axis from ANOVA permutations test: RDA1. Variance explained: $43 \%$

conditions. Concentration of Alternaria spores in the atmosphere increases when mean temperature rises. Positive, significant correlation with temperature has been reported in other cities around the world (Palmas and Cosentino 1990; Rosas et al. 1990; FernandezGonzales et al. 1993; Hjelmroos 1993; Mitakakis et al. 1997; Munuera Giner et al. 2001; Troutt and Levetin 2001).

Taking the whole our study period into consideration, we observed a decreasing linear trend in concentrations of both taxa spores and in the wind velocity in Szczecin. However, Munuera Giner et al. (2001) found the low wind velocity favouring high spore counts. Pasanen et al. (1991) found that Cladosporium spores required an airflow of at least $1.0 \mathrm{~m} \mathrm{~s}^{-1}$ for the spore release. The concentrations of Cladosporium spores in forest environments were measured by Kurkela (1997), who noted that the spore release was associated with the reduction in relative humidity and the increase in wind velocity. The highest concentrations occurred at relative humidity of $40-70 \%$ and when wind velocity increased from 0.5 to $1.0 \mathrm{~m} \mathrm{~s}^{-1}$. Lin and $\mathrm{Li}$ (2000) reported that fungi concentrations were reduced with increasing wind velocity up to $5 \mathrm{~m} \mathrm{~s}^{-1}$, but at higher wind velocities fungi concentrations increased. Other studies have found no relationship with the wind velocity (Sabariego et al. 2000; Burch and Levetin 2002). 
In Cracow we noted a significant increasing trend in temperature, significant decrease in humidity and tendency for the earlier season start and the earlier peak day. The variation in Alternaria daily spore concentrations in the atmosphere in relation to meteorological parameters was studied also by AnguloRomero et al. (1999). Daily concentrations varied positively with temperature and negatively with rainfall, but did not vary with humidity. Daily spore concentrations of Cladosporium and Alternaria were compared with daily weather data by Katial et al. (1997). Cladosporium daily spore concentrations were positively correlated with temperature and relative humidity and negatively with rainfall, while Alternaria spore concentrations were found not to be correlated with weather variables. Lyon et al. (1984) reported that once the spores were produced, the release of spores of anamorphic fungi was often greater with higher levels of the minimum wind velocity.

In Szczecin we observed the significantly earlier season start for Alternaria, tendency for the decrease in daily spore concentration and total number of spores. However, meteorological conditions did not explain changes in spore season characteristics (insignificant RDA models). The decrease in daily spore concentrations and total number of spores and the earlier season start in Szczecin seems no to be associated with meteorological conditions since they did not change significantly in the study period. In Cracow RDA models indicated that spore season parameters in over $40 \%$ were determined by meteorological conditions, mainly air temperature and wind velocity. If they increase, the peak value, total number of spores and their average concentrations in the season will also increase. The increase in temperature and the decrease in humidity in Cracow had the low impact on daily spore concentration (thus insignificant trends in spore abundance and spore season parameters). However, RDA models indicated the positive relation among the abundance of spores, air temperature and wind velocity. Differences in concentration between two cities are considered to be primarily due to local environmental conditions affecting the local fungi, which stimulate fungal growth.

The effects of temperature, relative humidity and rainfall are important for the source growth and material release. The same meteorological variable may have different effects on different phases of the life cycle, i.e. spore growth, source size, spore emission (Troutt and Levetin 2001). For example, humidity may enhance the spore growth and the increase in the spore size, but it may also reduce emission. The effect of any meteorological variable on spore concentration may differ from year to year because of extremes in other variables.

McCartney (1991) reviewing spore take-off mechanisms and the threshold wind velocity required for spore removal noted that information on the strength of spore attachment and values of threshold wind velocity is not known for the majority of fungi. Dispersal patterns are varied and appear to be different for different species and for the same species at different locations and times.

\section{Conclusions}

1. The study sites (Szczecin, Cracow) differed in higher average, maximum and minimum temperatures and in significantly lower relative humidity and average wind velocity in Cracow.

2. Concentrations of Alternaria and Cladosporium spores were significantly higher in Szczecin comparing to Cracow.

3. The decreasing trend in spore concentrations was observed in Szczecin.

4. In Szczecin redundancy analysis models did not explain changes in spore season characteristics.

5. In Cracow redundancy analysis models indicated the changes in spore season parameters in over $40 \%$ (caused mainly by air temperature and wind velocity).

Acknowledgments The authors wish to thank Maciej Gofron for preparing the map (Fig. 1) and Dr. Tomasz Wolski from the Faculty of Geosciences, University of Szczecin, for meteorological consultation.

Open Access This article is distributed under the terms of the Creative Commons Attribution 4.0 International License (http:// creativecommons.org/licenses/by/4.0/), which permits unrestricted use, distribution, and reproduction in any medium, provided you give appropriate credit to the original author(s) and the source, provide a link to the Creative Commons license, and indicate if changes were made.

\section{References}

Angulo-Romero, J., Mediavilla-Molina, A., \& DominguezVilches, E. (1999). Conidia of Alternaria in the atmosphere of the city of Cordoba, Spain, in relation to meteorological 
parameters. International Journal of Biometeorology, 43, 45-49.

British Aerobiology Federation. (1995). Airborne pollens and spores. A guide to trapping and counting (1st ed.). Rotherham, UK: Natl Pollen \& Hayfever Bureau.

Burch, M., \& Levetin, E. (2002). Effects of meteorological conditions on spore plumes. International Journal of Biometeorology, 46, 107-117.

Corden, J. M., \& Millington, W. M. (2001). The long term trends and seasonal variation of the aeroallergen Alternaria in Derby, UK. Aerobiologia, 17, 127-136.

Corden, J. M., Millington, W. M., \& Mullins, J. (2003). Long term trends and regional variation in the aeroallergen $\mathrm{Al}$ ternaria in Cardiff and Derby, UK. Are differences in climate and cereal production having an effect? Aerobiologia, 19, 191-199.

D’Amato, G. (1981). Allergia Respiratoria da Polline e da Miceti. Rome: Lombardo Edition.

Fernandez-Gonzales, D., Suarez-Cervera, M., Diaz-Gonzales, T., \& Valencia-Barrera, R. M. (1993). Airborne pollen and spores of Leon (Spain). International Journal of Biometeorology, 37, 89-95.

Fernández-Rodríguez, S., Sadyś, M., Smith, M., Torma-Molina, R., Skjøth, C. A., Maja-Manzano, J. M., et al. (2015). Potential sources of airborne Alternaria spp. spores in South-west Spain. Science of the Total Environment, 533, 165-176.

Gauch, H. G, Jr. (1982). Multivariate analysis in community structure. Cambridge: Cambridge University Press.

Ginn-Gofron, A., \& Strzelczak, A. (2008). Artificial neural network models of relationships between Alternaria spores and meteorological factors in Szczecin (Poland). International Journal of Biometeorology, 52, 859-868.

Grinn-Gofroń, A., \& Rapiejko, P. (2009). Occurrence of Cladosporium spp. and Alternaria spp. spores in Western, Northern and Central-Eastern Poland in 2004-2006 and relation to some meteorological factors. Atmospheric Research, 93, 747-758.

Grinn-Gofroń, A., \& Strzelczak, A. (2008). Artificial neural network models of relationships between Cladosporium spores and meteorological factors in Szczecin (Poland). Grana, 47, 304-314.

Gross, J. (2003). Variance inflation factors. R News, 3(1), 13-15.

Hill, M. O., \& Gauch, H. G. (1980). Detrended correspondence analysis, an improved ordination technique. Vegetatio, 42, 47-58.

Hirst, J. M. (1952). An automatic spore trap. Annals of Applied Biology, 39, 257-265.

Hjelmroos, M. (1993). Relationship between airborne fungal spore presence and weather variables. Grana, 32, 40-47.

Iglesias, I., Rodríguez-Rajo, J., \& Méndez, J. (2007). Evaluation of the different Alternaria prediction models on a potato crop in A Limia (NW of Spain). Aerobiologia, 2, 27-34.

Infante, F., Alba, F., Caño, M., Castro, A., Domínguez, E., Méndez, J., \& Vega, A. (1999a). A comparative study of the incidence of Alternaria conidia in the atmosphere of five Spanish cities. Polen, 10, 7-15.

Infante, F., Castro, A., Domínguez, E., Guardia, A., Méndez, J., Sabariego, S., \& Vega, A. (1999b). A comparative study of the incidence of Cladosporium conidia in the atmosphere of five Spanish cities. Polen, 10, 17-25.
Katial, R. K., Zhang, Y., Jones, R. H., \& Dyer, P. D. (1997). Atmospheric mould spore counts in relation to meteorological parameters. International Journal of Biometeorology, 41, 17-22.

Konopińska, A. (2004). Monitoring of Alternaria Ness and Cladosporium Link airborne spores in Lublin (Poland) in 2002. Annals of Agricultural and Environmental Medicine, 11, 347-349.

Kurkela, T. (1997). The number of Cladosporium conidia in the air in different weather conditions. Grana, 36, 54-61.

Kurup, V. P., Shen, H. D., \& Vijay, H. (2002). Immunobiology of fungal allergens. International Archives of Allergy and Immunology, 129, 181-188.

Legendre, P., \& Legendre, L. (1998). Numerical ecology. Amsterdam: Elsevier.

Legendre, P., Oksanen, J., \& ter Braak, C. J. F. (2011). Testing the significance of canonical axes in redundancy analysis. Methods in Ecology and Evolution, 2, 269-277.

Li, D.-W., \& Kendrick, B. (1995). A year-round study of functional relationships of airborne fungi with meteorological factors. International Journal of Biometeorology, 39, 74-80.

Lin, W.-H., \& Li, C.-S. (2000). Associations of fungal aerosols, air pollutants and meteorological factors. Aerosol Science and Technology, 32, 359-368.

Lyon, F. L., Kramer, C. L., \& Eversmeyer, M. G. (1984). Variation of airspora in the atmosphere due to weather conditions. Grana, 23, 177-181.

Mann, H. B., \& Whitney, D. R. (1947). On a test of whether one of two random variables is stochastically larger than the other. Annals of Mathematical Statistics, 18, 50-60.

McCartney, H. A. (1991). Airborne dissemination of plants pathogens. Journal of Applied Bacteriology, 70, 49-59.

Mitakakis, T., Clift, A., \& McGee, P. A. (2001). The effect of local cropping activities and weather on the airborne concentration of allergenic Alternaria spores in rural Australia. Grana, 40, 230-239.

Mitakakis, T., Ong, E. K., Stevens, A., Guest, D., \& Knox, R. B. (1997). Incidence of Cladosporium, Alternaria and total fungal spores in the atmosphere of Melbourne (Australia) over 3 years. Aerobiologia, 13, 83-90.

Munuera Giner, M., Carrion Garcia, J. S., \& Navarro Camacho, C. (2001). Airborne Alternaria spores in SE Spain (1993-98): Occurrence patterns, relationship with weather variables and prediction models. Grana, 40, 111-118.

Oksanen, J., \& Minchin, P. R. (1997). Instability of ordination results under changes in input data order: Explanations and remedies. Journal of Vegetation Science, 8, 447-454.

Palmas, F., \& Cosentino, S. (1990). Comparison between fungal airspora concentration at two different cities in the South of Sardinia. Grana, 29, 87-95.

Palmer, W. (1993). Putting things in even better order: The advantages of canonical correspondence analysis. Ecology, 74, 2215-2230.

Pasanen, A. L., Pasanen, P., Jantunen, M. J., \& Kalliokoski, P. (1991). Significance of air humidity and air velocity for fungal spore release into the air. Atmospheric Environment, $25,459-462$.

Pepeljnjak, A., \& Segovic, M. (2003). Occurrence of fungi in air and on plants in vegetation of different climatic regions in Croatia. Aerobiologia, 19, 11-19. 
Peternel, R., Culig, J., \& Hrga, L. (2004). Atmospheric concentrations of Cladosporium spp. and Alternaria spp. spores in Zagreb (Croatia) and effects of some meteorological factors. Annals of Agriculture and Environmental Medicine, 11, 303-307.

Ricci, S., Bruni, M., Meriggi, R., \& Corsico, R. (1995). Aerobiological monitoring of Alternaria fungal spores: a comparison between surveys in 1992 and 1993 and local meteorological conditions. Aerobiologia, 11, 195-1999.

Rosas, I., Escamilla, B., Calderon, C., \& Mosino, P. (1990). The daily variation of airborne fungal spores in Mexico City. Aerobiologia, 6, 153-158.

Sabariego, S., Diaz de la Guardia, C., \& Alba, F. (2000). The effect of meteorological factors on the daily variation of airborne fungal spores in Granada (southern Spain). International Journal of Biometeorology, 44, 1-5.

Sadyś, M., Skjøth, C. A., \& Kennedy, R. (2014). Determination of Alternaria spp. habitats using 7-day volumetric spore trap, Hybrid Single Particle Lagrangian Integrated Trajectory model and geographic information system. Urban Climate,. doi:10.1016/j.uclim.2014.08.005.

Spieksma F. T. M. (1995). Outdoor atmospheric mould spores in Europe. In XIV European Congress of Allergology and Clinical Immunology (pp. 625-630). Madrid.
StatSoft, Inc. (2011). STATISTICA (data analysis software system), version 10. www.statsoft.com

Stępalska, D., Harmata, K., Kasprzyk, I., Myszkowska, D., \& Stach, A. (1999). Occurrence of airborne Cladosporium and Alternaria spores in Southern and Central Poland in 1995-1996. Aerobiologia, 15, 39-47.

Stępalska, D., \& Wołek, J. (2005). Variation in fungal spore concentrations of selected taxa associated to weather conditions in Cracow, Poland, in 1997. Aerobiologia, 21, 43-52.

ter Braak, C. J. F. (1995). Ordination. In R. H. G. Jongman, C. J. F. ter Braak, \& O. F. R. van Tongeren (Eds.), Data analysis in community and landscape ecology (pp. 1-292). Cambridge: Cambridge University Press.

ter Braak, C. J. F., \& Prentice, I. C. (1988). A theory of gradient analysis. Advances in Ecological Research, 18, 271-313.

The R Foundation for Statistical Computing. (2009). R version 2.10.1.

Troutt, C., \& Levetin, E. (2001). Correlation of spring spore concentrations and meteorological conditions in Tulsa, Oklahoma. International Journal of Biometeorology, 45, 64-74.

Woś, A. (1999). Klimat Polski (Climate of Poland). Warszawa: PWN. 